\title{
Psychological, social, and mechanical work exposures and disability retirement: a prospective registry study
}

\author{
Jan S. Emberland", Morten Birkeland Nielsen and Stein Knardahl
}

\begin{abstract}
Background: Relations between several occupational psychological and social factors and disability retirement remain largely unexplored. Knowledge of which specific aspects of the work environment that affect risk of disability is a prerequisite for the success of organizational interventions aiming to prevent premature work force exit. The objective of the present study was to determine contributions to registered disability retirement by a broad range of psychological and social work exposures while taking into account effects of mechanical exposure.

Methods: Written consent was obtained from 13012 employees (96 organizations) representing a wide range of occupations, to link their survey responses to data from the Norwegian national registry of disability compensation. Median follow-up time was 5.8 years. To determine effects of self-reported work exposures on risk of disability retirement hazard ratios (HR) and $99 \%$ confidence intervals $(99 \% \mathrm{Cl}$ ) were calculated with Cox regression analysis. Effects of sex, age group, skill level, sickness absence in the last three years, and work exposures estimated to be confounders were accounted for. Post hoc stratification by sex was conducted to explore if identified predictors affected risk of disability retirement differently in men compared to women.
\end{abstract}

Results: Contributors to higher risk of disability retirement were "role conflict" (high level HR $1.5599 \% \mathrm{Cl} 1.07$ to 2.24) and "physical workload" (high level HR $1.9399 \% \mathrm{Cl} 1.39$ to 2.68). Contributors to lower risk of disability retirement were "positive challenge" (high level HR 0.56 99\% Cl 0.34 to 0.93), "fair leadership" (high level HR 0.56 99\% Cl 0.39 to 0.81), and "control over work intensity" (high level HR 0.62, 99\% Cl 0.47 to 0.82). Direction of effects was not dependent on sex in any of the five identified predictors.

Conclusions: Several specific psychological and social work factors are independent contributors to risk of disability retirement. In order to prevent premature work force exit workplace interventions should consider targeting the predictors identified by the present study.

Keywords: Disability retirement, Occupational, Psychosocial, Mechanical, Registry data, Prospective, Hazard ratio

\section{Background}

Exit from working life due to disability incurs large costs for societies as well as challenges to the quality of life of persons. Premature exit may result from impacts of biological/medical, psychological, and social conditions on functioning [1]. Still, the potential influences of a variety of non-physical work environment conditions on disability retirement have previously been devoted little attention. The present study aimed to determine which of a broad

\footnotetext{
* Correspondence: jse@stami.no

Department of Work Psychology and -Physiology, National Institute of

Occupational Health, P.O. Box 8149 DepN-0033 Oslo, Norway
}

range of specific occupational psychological and social factors that may contribute to disability retirement.

The workplace is an arena where individuals face challenges inherent in work tasks and social interactions. Work also provides opportunities for positive experiences from achievement and friendship. For many people, the job is a major source of feedback, fulfillment, and personal identity which in turn may promote work motivation, health, and work ability. Hence, conditions at work may contribute to disability retirement in several ways, e.g. by (I) influencing health and work ability, by (II) influencing motivation to 
work, or by (III) making work too demanding relative to work ability (competence) in the jobs that are available.

A 2011 systematic review of psychological and social work factors contributing to disability retirement [2] revealed that only a limited number of factors have been examined. The majority of the reviewed studies sought to identify contributions of "low control," "psychological demands," and "social support." In many of these, as well as subsequent studies on registered work disability (e.g. [3-5]) it is apparent that the Job Content Questionnaire (JCQ; [6]) has been the preferred instrument to measure psychological and social work factors. This instrument groups several specific factors under broad demand and control dimensions, which raises the possibility that factors with opposite effects are grouped together under the same heading. However, knowledge of specific contributors to disability is arguably a prerequisite for developing practical interventions at the workplace.

Recent studies have shown that psychological and social factors other than the dimensions assessed with the JCQ instrument contribute to health symptoms (e.g. $[7,8])$ and perceived work ability [9]. Hence, it seems timely to broaden the scope by exploring contributions to disability retirement by a wider range of non-physical work factors.

Biomechanical workload has received considerable attention in relation to registered work disability, and several studies have examined effects of both mechanical and psychological/social work factors $[4,5,10,11]$. Based on previous publications it remains somewhat unclear if mechanical workload plays an important role in explaining associations between non-physical occupational factors and work disability. While the main objective was to determine contributions of a broad range of psychological and social work factors to publicly registered disability retirement, the present study also sought to account for effects of mechanical work exposure.

\section{Methods}

\section{Study design}

The current study is part of a full-panel prospective study of work factors contributing to health, work ability, absence, and exit from working life in Norway. Employees were invited to participate in a web-based survey containing questions on background information, psychological, social, and mechanical work factors, work organization, mastery of work, attitudes towards work, organizational change, personality, health behavior, coping strategies, mental health, health complaints, and work ability. Each employee received a letter containing information about the survey and a personalized code for logging into the web-based questionnaire. A paper version of the questionnaire was made available upon request. Written information specified the strict confidentiality guidelines and informed about the license for data collection granted by the Norwegian Data Inspectorate. The organizations from which employees were recruited provided data on employees' departmental affiliation, home address, and occupational title according to the Norwegian standard classification of the occupations (STYRK) - a system developed by Statistics Norway based on the International Classification of Occupation (ISCO-88). In return for participation in the project, the organizations received written reports and oral presentations of results with the objective of supporting management and personnel in the process of monitoring their work conditions.

\section{Population}

Employees were recruited from 96 companies representing a broad spectrum of occupational sectors including health care, education, government and public administration, engineering, project management, industry, and non-profit organizations. A total of 30585 subjects were invited to participate in the period 2004 to 2014. At the time of invitation 28833 (94.3\%) subjects were aged 1862 years and thus eligible for disability retirement benefits. Subjects above the age of 62 were excluded as they are additionally entitled to early age pension. Of the invited aged 18-62, 17789 (61.7\%) responded to the questionnaire survey. Written consent was obtained from 13 $012(73.1 \%)$ subjects and enabled linking these individuals' questionnaire responses to data from the national registry of disability compensation maintained by the Norwegian Labour and Welfare Administration (NAV). Based on information from this registry subjects were excluded from the present study if having incomplete history of work disability (emigration before response, $n=76$; $0.6 \%$ ) or having received disability retirement compensation (due to some proportion of disability) prior to response $(n=498 ; 3.8 \%$ ). Thus, the final cohort (Fig. 1) consisted of 12 438 subjects ( $95.6 \%$ of the participants; mean age 41.8 years; $55.5 \%$ women) with a median follow-up time of 5.8 years.

\section{Ethical approval}

The project has been approved by the Regional Committees for Medical and Health Research Ethics (REC) in Norway and has permission from The Norwegian Data Protection Authority. The research was carried out in compliance with the World Medical Association Declaration of Helsinki and written informed consent was obtained from all study participants (for details see [12]).

\section{Outcome: disability retirement}

Disability retirement was defined as the subject receiving disability pension compensation from the Norwegian Labour and Welfare Administration (NAV). Unlike reimbursement for sickness absence, the requirement for receiving disability pension is that the magnitude of work inability is at least 50\% [13]. Compensation criteria 
30585 subjects from 96 companies invited to participate in 2004-2014

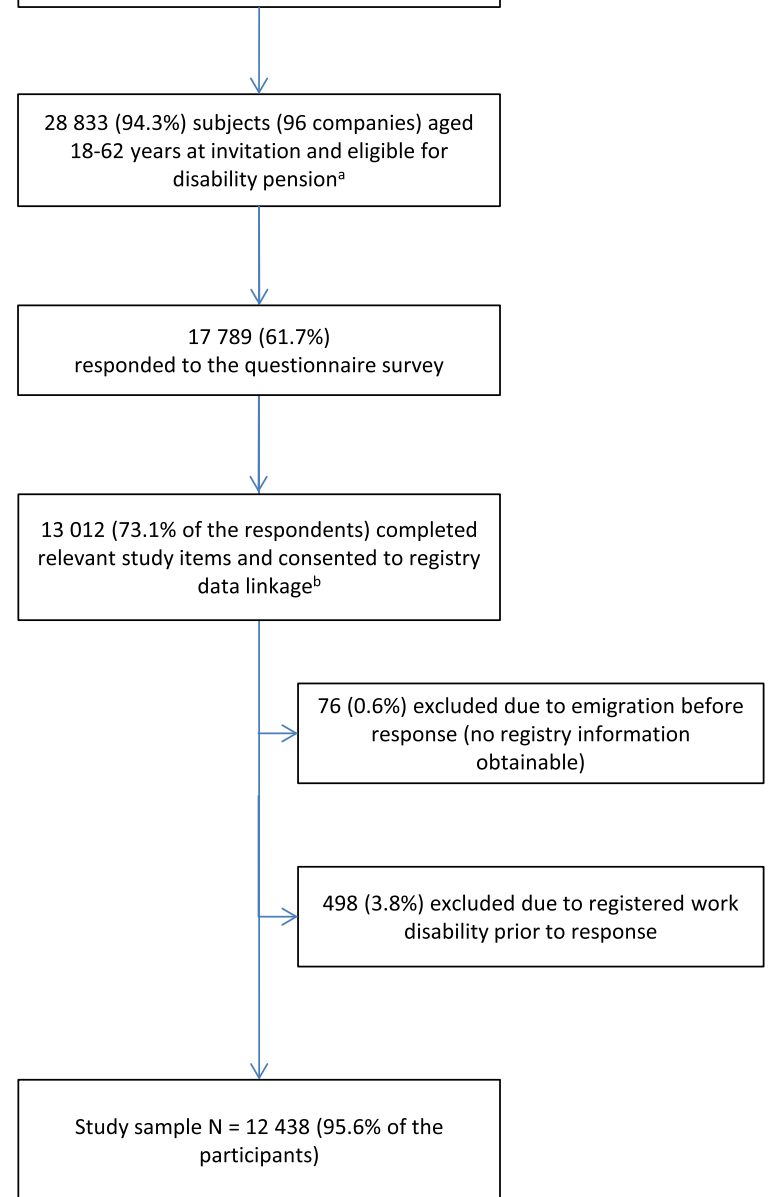

Fig. 1 Flow diagram depicting the selection process. ${ }^{a}$ Employees above 62 years of age are additionally eligible for statutory early age pension and thus excluded from the present study. ${ }^{b}$ National registers maintained by the Norwegian Labour and Welfare Administration

must be substantiated by an extensive physician's certificate and confirmed by examinations (which includes assessment of job specific capacities) undertaken by specialized (usually medical) representatives from a local NAV office. For the respondents consenting to registry linkage we had access to information on disability pension compensation recorded in the NAV registry up to 1 January 2015 (the end of the present study's follow-up period).

\section{Psychological, social, and mechanical work factors}

Psychological and social exposures were measured by the General Nordic Questionnaire for psychological and social factors at work $\left(\mathrm{QPS}_{\text {Nordic }}\right)$. Psychometric evaluations of $\mathrm{QPS}_{\text {Nordic }}$ have shown high validity and reliability of the scales included in the present study [14]. Reliability analyses indicate that the factors are consistent across a wide range of occupational groups [15].
The psychological and social scales covered job demands, control at work, predictability at work, role expectation, leadership, and organizational culture and climate (see Table 3). A complete list of scale items has been published elsewhere [14, 15]. Responses to items were given on a 5-point scale; 1 "very seldom or never," 2 "somewhat seldom," 3 "sometimes," 4 "somewhat often," and 5 "very often or always."

Mechanical exposure was measured with two items; physical workload, and working with arms raised to or above shoulder level (single item). Physical workload was assessed by measuring the extent to which subjects were lifting or handling objects that weigh approximately $1-5 \mathrm{~kg}, 6-15 \mathrm{~kg}$, and more than approximately $15 \mathrm{~kg}$ with own muscular strength. Response categories for both measures were; 1 "seldom or never," 2 "sometimes," 3 "daily," and 4 "many times per day."

To address dose-response relationships, scale scores were categorized into three exposure levels. In line with previously published analyses from parts of the same cohort $[8,9]$ scores from 1.00 through 2.60 were classified as "low"; 2.61 through 3.40 as "middle"; and 3.41 through 5.00 were classified as "high" exposure, respectively. For the four-level measures (mechanical exposures) scores from 1.00 through 2.50 were classified as "low"; 2.51 through 3.50 as "middle," and 3.51 through 4.00 as "high" exposure, respectively.

\section{Statistical analysis}

Statistical analyses were conducted with SPSS version 22.0 (IBM, Armonk, NY) and with the survival package [16] for $\mathrm{R}$ version 3.2.2.

Non-response analysis was conducted to determine if background variables influenced whether subjects responded at baseline. Binary logistic regressions were run with response status as outcome. The effects of age, sex, occupational group, and skill level were estimated separately. Since the occupational group variable does not have a clear intrinsic order this variable was treated as nominal. Thus, the effects of each of the 10 occupational categories on response status were calculated by using the combination of all other occupational groups as reference.

Hazard ratios were calculated with Cox regression analysis to determine effects of background variables and 16 work exposures on disability retirement. Analyses were run separately with each background/work exposure variable as independents. Since multiple analyses were performed 99\% confidence intervals were chosen in order to reduce the risk of type 1 error. Due to the clearly higher hazard ratio for subsequent work disability in women (Table 2) post hoc analysis with stratification by sex was conducted to uncover if the identified predictors in the primary analysis (see Table 3 ) were differentially related to 
work disability according to sex. In order to calculate a single effect estimate for each predictor (to be compared across sexes), exposure variables were entered as continuous in these analyses.

As recommended for studies of healthy populations [17] attained age (at censoring/event) was the underlying time scale in the analyses (except in the non-response analysis with age group as the primary predictor) rather than "time-on-study" (i.e. years since baseline response).

Interactions between each background/work exposure variable and the logarithm of the follow-up time i.e. age in years, (for age group; time since response) were determined by tests of non-zero slopes followed by graphical plots of scaled Schoenfeld residuals. The tests indicated no violations of the proportional hazards assumption (for all variables: $P>0.05$ ).

Follow-up time was calculated from the calendar date subjects responded to the web-based questionnaire. For subjects completing the paper version of the questionnaire $(n=1106)$ and for some of the web responders $(n=882)$ information on actual response date was not obtainable. In these cases response date was set to the last possible date of response for all employees in their respective company. Follow-up ended at the time point of being granted disability pension $(n=553)$, emigration $(n=42)$, death $(n=39)$, or 1 January $2015(n=10407)$ whichever came first. At the time of this study data from the old age pension registry had not been obtained. Thus, subjects were also censored if they reached the eligible age for early statutory pension (which is the first day of the month following the 62nd birthday) before the end of follow-up $(n=1397)$.

\section{Potential confounding variables}

The effects of sex, skill level, age group, and sickness absence (in the 3 years preceding baseline response) were accounted for in all analyses of work exposures and disability retirement. Skill level was determined by recoding the occupational groups (ISCO-88) in agreement with the International Standard for Classification of Education (ISCED). In cases where no information on occupational group (ISCO-88) had been provided by the subjects' respective companies, missing values were substituted with self-reported skill level information $(n=102)$. Baseline age was categorized into; $18-29,30-39,40-49$, and 5062 years, to account for potential cohort effects [17].

Some chronic illnesses may lead to reductions in certain work exposure levels $[18,19]$. Also, a number of chronic diseases are linked with risk of disability pensioning [20]. Thus, the analyses were adjusted for sickness absence prior to baseline response caused by cardiovascular disease, respiratory illnesses, cerebrovascular disease, diabetes, or cancer $[21,22]$. This information was obtained from the sickness absence registry maintained by the Norwegian
Labour and Welfare Administration and limited to the 3 years prior to baseline participation.

The observed effect of each work exposure on work disability may be confounded by the effects of other work exposures. However, since the scales are interrelated $[14,15]$ simultaneously controlling for all other work exposures is likely to result in overadjustment. Thus, a strategy described by Rothman et al. [23] was utilized to identify influence by other work exposures above a certain threshold level. First, the effect of an exposure on disability retirement was estimated. Subsequently, one other exposure was added to the model. If the effect estimate of the original exposure changed by more than $10 \%$ in the second model the added exposure was defined as a confounder [23]. This procedure was carried out for each of the 16 work exposure measures. The influence of each of the other 15 work exposure measures was estimated.

\section{Results}

\section{Non-response analysis}

Sex was not predictive of responding at baseline $(P>0.05$; Table 1). Subjects aged $>29$ (i.e. $30-39,40-49$, and 50-62) exhibited higher odds of responding compared to the lowest age group (for all: $P<0.05$ ). The non-response analyses further revealed that the groups; legislators/senior officials/managers, professionals, and clerks exhibited significantly higher odds of responding at baseline compared to all other occupational classes (combined). Lower odds of responding were detected for service workers/shop/market sales workers and plant/machine operators/assemblers. The analyses of skill level indicated that subjects with competence level corresponding to less than 4 years of higher education exhibited lower likelihood of responding at baseline. Subjects with unspecified competence level (this being legislators/senior officials/managers) had a clearly higher likelihood of responding compared to subjects with competence level equivalent to minimum 4 years of higher education.

Background characteristics predictive of disability retirement Women exhibited a higher risk of disability retirement compared to men $(P<0.05$; Table 2$)$. Being in the age group 50 to 62 was associated with an increase in risk of disability retirement compared to being $<30$ years of age. Also, differences in risk of disability retirement were found between the occupational groups; service workers/ shop/market sales workers exhibited higher risk compared to the other occupational groups combined. Legislators/ senior officials/managers, professionals, and craft and related trades workers showed lower risk. In the analyses of skill level, lower levels were associated with higher risk of disability retirement. One exception was the group with unspecified requirements for competence level (this being legislators/senior officials/managers) which showed a 
Table 1 Sample characteristics and their associations with baseline response

\begin{tabular}{|c|c|c|c|c|c|c|c|}
\hline \multirow{3}{*}{ Background variable } & \multicolumn{4}{|c|}{$\begin{array}{l}\text { Employees aged } 18-62 \text { years } \\
(N=28833)\end{array}$} & \multicolumn{3}{|c|}{$\begin{array}{l}\text { Association with baseline } \\
\text { response }\end{array}$} \\
\hline & \multicolumn{2}{|l|}{$\begin{array}{l}\text { Participants } \\
(n=13012) \\
\end{array}$} & \multicolumn{2}{|c|}{$\begin{array}{l}\text { Non-participants } \\
(n=15821)\end{array}$} & \multirow[b]{2}{*}{ OR } & \multirow[b]{2}{*}{$95 \% \mathrm{Cl}$} & \multirow[b]{2}{*}{$P$-value } \\
\hline & $\mathrm{N}$ & $\%$ & $\mathrm{~N}$ & $\%$ & & & \\
\hline \multicolumn{8}{|l|}{ Sex } \\
\hline Male & 5733 & 44.06 & 7108 & 44.93 & 1.00 & & \\
\hline Female & 7279 & 55.94 & 8669 & 54.79 & 1.04 & $0.99-1.09$ & 0.091 \\
\hline Missing data & 0 & 0 & 44 & 0.28 & & & \\
\hline Age in years, mean (SD) & $41.91(10.20)$ & & $40.43(11.19)$ & & & & \\
\hline$<30$ & 1725 & 13.26 & 3228 & 20.40 & 1.00 & & \\
\hline $30-39$ & 3791 & 29.13 & 4397 & 27.79 & 1.61 & $1.50-1.74$ & $<0.001^{*}$ \\
\hline $40-49$ & 4078 & 31.34 & 4222 & 26.69 & 1.81 & $1.68-1.94$ & $<0.001^{*}$ \\
\hline $50-62$ & 3418 & 26.27 & 3974 & 25.12 & 1.61 & $1.49-1.73$ & $<0.001^{*}$ \\
\hline \multicolumn{8}{|l|}{ Classification of occupation ${ }^{a}$} \\
\hline Legislators, senior officials, and managers & 1120 & 8.61 & 580 & 3.67 & 1.83 & $1.65-2.03$ & $<0.001^{*}$ \\
\hline Professionals & 3662 & 28.14 & 2837 & 17.93 & 1.25 & $1.18-1.32$ & $<0.001^{*}$ \\
\hline Technicians and associate professionals & 3641 & 27.98 & 3336 & 21.09 & 0.99 & $0.94-1.05$ & 0.797 \\
\hline Clerks & 728 & 5.59 & 527 & 3.33 & 1.28 & $1.14-1.43$ & $<0.001^{*}$ \\
\hline Service workers and shop and market sales workers & 2940 & 22.59 & 3626 & 22.92 & 0.66 & $0.63-0.70$ & $<0.001^{*}$ \\
\hline Skilled agricultural and fishery workers & 1 & $<0.01$ & 7 & 0.04 & 0.13 & $0.02-1.06$ & 0.056 \\
\hline Craft and related trades workers & 394 & 3.03 & 394 & 2.49 & 0.91 & $0.79-1.05$ & 0.186 \\
\hline Plant and machine operators and assemblers & 44 & 0.34 & 95 & 0.60 & 0.42 & $0.29-0.60$ & $<0.001^{*}$ \\
\hline Elementary occupations & 322 & 2.47 & 312 & 1.97 & 0.94 & $0.81-1.10$ & 0.435 \\
\hline Armed forces and unspecified & 0 & 0 & 1 & $<0.01$ & - & & - \\
\hline Missing data & 160 & 1.23 & 4106 & 25.95 & & & \\
\hline \multicolumn{8}{|l|}{ Skill level ${ }^{\mathrm{b}}$} \\
\hline Competence equivalent to minimum 4 years of higher education ( $>15$ years) & 3675 & 28.24 & 2848 & 18.00 & 1.00 & & \\
\hline Competence equivalent to $1-3$ years of higher education (13-15 years) & 3683 & 28.30 & 3373 & 21.32 & 0.85 & $0.79-0.91$ & $<0.001^{*}$ \\
\hline Competence equivalent to high school (10-12 years) & 4150 & 31.89 & 4713 & 29.79 & 0.68 & $0.64-0.73$ & $<0.001^{*}$ \\
\hline Occupations that do not require high school (<10 years) & 336 & 2.58 & 324 & 2.05 & 0.80 & $0.69-0.94$ & $0.008^{*}$ \\
\hline Occupations with unspecified requirements for competence & 1120 & 8.61 & 581 & 3.67 & 1.49 & $1.34-1.67$ & $<0.001^{*}$ \\
\hline Missing data & 48 & 0.37 & 3982 & 25.17 & & & \\
\hline
\end{tabular}

$N$ number of subjects, $O R$ odds ratio, $C l$ confidence interval, SD standard deviation

a Treated as binary variables. Each occupational group coded as 1 while all other listed occupational groups coded as 0 (reference) in each analysis

${ }^{b}$ Occupations grouped into the level of competence expected for the respective occupations. In cases with no information from company records missing values

were substituted by, if available, self-reported skill level

* $P<0.05$

lower risk of disability retirement compared to the reference group (subjects with minimum 4 years of higher education). Finally, subjects with sickness absence due to a range of chronic diseases registered in the 3 -year period prior to baseline response exhibited higher risk of disability retirement $(P<0.05)$.

\section{Work exposures predictive of disability retirement}

Higher risk of disability retirement was associated with the highest baseline levels of role conflict and physical workload $(P<0.01$; Table 3$)$. Lower risk of disability retirement was predicted by the highest baseline levels of positive challenge, control over work intensity, and middle and high level of fair leadership $(P<0.01)$.

Post hoc stratification by sex with the five identified contributors revealed that the risk estimates for women and men were in the same direction for all of the predictors (Table 4). Also, differences in the hazard risk ratios were minor comparing the sex-specific effects of role conflict and control over work intensity. With a risk ratio difference of more than $10 \%$ two of the factors were notably more protective of disability retirement in men i.e. 
Table 2 Baseline sample characteristics as predictors of disability retirement

\begin{tabular}{|c|c|c|c|c|c|c|}
\hline Background variable & Number & $\begin{array}{l}\text { Disability cases } \\
\mathrm{n}\end{array}$ & $\%^{a}$ & $H R^{b}$ & $95 \% \mathrm{Cl}$ & $P$-value \\
\hline \multicolumn{7}{|l|}{ Sex } \\
\hline Male & 5536 & 111 & 2.01 & 1.00 & & \\
\hline Female & 6902 & 442 & 6.40 & 3.30 & $2.68-4.06$ & $<0.001^{*}$ \\
\hline Age in years, mean (SD) & $41.79(10.23)$ & $44.02(9.80)$ & & & & \\
\hline$<30$ & 1697 & 58 & 3.42 & 1.00 & & \\
\hline $30-39$ & 3641 & 117 & 3.21 & 0.88 & $0.64-1.20$ & 0.416 \\
\hline $40-49$ & 3863 & 184 & 4.76 & 1.34 & $0.99-1.80$ & 0.051 \\
\hline $50-62$ & 3237 & 194 & 5.99 & 2.31 & $1.72-3.09$ & $<0.001^{*}$ \\
\hline \multicolumn{7}{|l|}{ Classification of occupation ${ }^{c}$} \\
\hline Legislators, senior officials, and managers & 1101 & 26 & 2.36 & 0.35 & $0.23-0.51$ & $<0.001^{*}$ \\
\hline Professionals & 3510 & 112 & 3.19 & 0.62 & $0.51-0.77$ & $<0.001^{*}$ \\
\hline Technicians and associate professionals & 3476 & 153 & 4.40 & 1.04 & $0.86-1.25$ & 0.700 \\
\hline Clerks & 690 & 46 & 6.67 & 1.30 & $0.96-1.76$ & 0.092 \\
\hline Service workers and shop and market sales workers & 2794 & 173 & 6.19 & 2.26 & $1.89-2.71$ & $<0.001^{*}$ \\
\hline Skilled agricultural and fishery workers & 1 & 0 & 0 & - & - & - \\
\hline Craft and related trades workers & 358 & 4 & 1.12 & 0.26 & $0.10-0.70$ & $0.008^{*}$ \\
\hline Plant and machine operators and assemblers & 39 & 3 & 7.69 & 1.72 & $0.55-5.36$ & 0.348 \\
\hline Elementary occupations & 316 & 22 & 6.96 & 1.52 & $0.99-2.32$ & 0.056 \\
\hline Armed forces and unspecified & 0 & 0 & 0 & - & - & - \\
\hline Missing data & 153 & 14 & 9.15 & & & \\
\hline \multicolumn{7}{|l|}{ Skill level ${ }^{d}$} \\
\hline Competence equivalent to minimum 4 years of higher education ( $>15$ years) & 3523 & 113 & 3.21 & 1.00 & & \\
\hline Competence equivalent to 1-3 years of higher education (13-15 years) & 3517 & 156 & 4.44 & 1.48 & $1.16-1.88$ & $0.002^{*}$ \\
\hline Competence equivalent to high school (10-12 years) & 3924 & 232 & 5.91 & 2.23 & $1.78-2.79$ & $<0.001^{*}$ \\
\hline Occupations that do not require high school (<10 years) & 329 & 24 & 7.29 & 2.16 & $1.39-3.35$ & $0.001^{*}$ \\
\hline Occupations with unspecified requirements for competence & 1101 & 26 & 2.36 & 0.53 & $0.35-0.82$ & $0.004^{*}$ \\
\hline Missing data & 44 & 2 & 4.55 & & & \\
\hline \multicolumn{7}{|l|}{ Sickness absence ${ }^{\mathrm{e}}$} \\
\hline No & 11911 & 493 & 4.14 & 1.00 & & \\
\hline Yes & 527 & 60 & 11.39 & 2.17 & $1.66-2.83$ & $<0.001^{*}$ \\
\hline
\end{tabular}

$N$ number of subjects, $H R$ hazard ratio, $C I$ confidence interval, $S D$ standard deviation

${ }^{\text {aP }}$ ercentage of registered disability pension cases within each category

${ }^{\mathrm{b}}$ Crude effect

'Treated as binary variables. Each occupational group coded as 1 while all other listed occupational groups coded as 0 (reference) in each analysis

dOccupations grouped into the level of competence expected for the respective occupations. In cases with no information from company records missing values were substituted by, if available, self-reported skill level

eDue to respiratory illnesses, cardiovascular disease, cerebrovascular disease, diabetes, or cancer in the 3 years prior to response

*P $P<0.05$

positive challenge $\left(\mathrm{HR}_{\mathrm{men}} 0.77\right.$, $\mathrm{CI} 0.54-1.11$ vs $\mathrm{HR}_{\text {women }}$ 0.96, CI 0.80-1.15) and fair leadership $\left(\mathrm{HR}_{\text {men }} 0.74, \mathrm{CI}\right.$ 0.57-0.96 vs $\mathrm{HR}_{\text {women }}$ 0.86, CI 0.75-0.99). Further, with a risk ratio difference of $26.2 \%$ physical workload was a stronger risk factor to disability retirement in men than in women $\left(\mathrm{HR}_{\text {men }} 1.68 \mathrm{CI} 1.22-2.32\right.$ vs $\mathrm{HR}_{\text {women }} 1.24 \mathrm{CI}$ 1.06-1.45). Although differences in magnitude of effects were detected the confidence intervals for all factors overlapped in range across the sexes.

\section{Discussion}

The present results clearly indicated that in addition to physical workload higher levels of several psychological and social work exposures independently predict subsequent disability retirement. A lower risk of disability retirement was predicted by the factors positive challenge, control over work intensity, and fair leadership. Role conflict and physical workload were the most prominent predictors of higher risk of disability retirement. Of these five factors positive 
Table 3 Psychological, social, and mechanical work factors as predictors of disability retirement

\begin{tabular}{|c|c|c|c|c|}
\hline Factor & Number & $H R^{a}$ & $99 \% \mathrm{Cl}$ & $\begin{array}{l}P \text {-value } \\
\text { for trend }\end{array}$ \\
\hline Decision demands & & & & 0.411 \\
\hline Low & 986 & 1.00 & & \\
\hline Middle & 4890 & 0.82 & $0.56-1.21$ & \\
\hline High & 5958 & 0.86 & $0.58-1.26$ & \\
\hline Quantitative demands & & & & 0.035 \\
\hline Low & 4012 & 1.00 & & \\
\hline Middle & 4686 & 1.14 & $0.87-1.49$ & \\
\hline High & 3318 & 1.28 & $0.95-1.73$ & \\
\hline Role clarity & & & & 0.913 \\
\hline Low & 386 & 1.00 & & \\
\hline Middle & 1478 & 0.60 & $0.30-1.18$ & \\
\hline High & 10283 & 0.70 & $0.39-1.25$ & \\
\hline Role conflict & & & & 0.020 \\
\hline Low & 5797 & 1.00 & & \\
\hline Middle & 5042 & 1.25 & $0.99-1.59$ & \\
\hline High & 1312 & 1.55 & $1.07-2.24$ & \\
\hline Positive challenge ${ }^{b}$ & & & & 0.027 \\
\hline Low & 440 & 1.00 & & \\
\hline Middle & 1983 & 0.68 & $0.40-1.17$ & \\
\hline High & 8675 & 0.56 & $0.34-0.93$ & \\
\hline Control over work intensity & & & & $<0.001$ \\
\hline Low & 3461 & 1.00 & & \\
\hline Middle & 2406 & 0.84 & $0.62-1.14$ & \\
\hline High & 6227 & 0.62 & $0.47-0.82$ & \\
\hline Decision control $^{c}$ & & & & 0.005 \\
\hline Low & 4057 & 1.00 & & \\
\hline Middle & 4374 & 0.92 & $0.70-1.20$ & \\
\hline High & 3135 & 0.70 & $0.48-1.01$ & \\
\hline $\begin{array}{l}\text { Predictability during the next } \\
\text { month }\end{array}$ & & & & 0.998 \\
\hline Low & 568 & 1.00 & & \\
\hline Middle & 1423 & 1.70 & $0.88-3.32$ & \\
\hline High & 10159 & 1.22 & $0.66-2.23$ & \\
\hline Support from immediate superior ${ }^{d}$ & & & & 0.826 \\
\hline Low & 989 & 1.00 & & \\
\hline Middle & 2517 & 1.06 & $0.67-1.67$ & \\
\hline High & 8343 & 0.96 & $0.60-1.52$ & \\
\hline Empowering leadership & & & & 0.175 \\
\hline Low & 2930 & 1.00 & & \\
\hline Middle & 4260 & 0.80 & $0.60-1.05$ & \\
\hline High & 4935 & 0.86 & $0.65-1.13$ & \\
\hline Fair leadership & & & & 0.001 \\
\hline
\end{tabular}

Table 3 Psychological, social, and mechanical work factors as predictors of disability retirement (Continued)

\begin{tabular}{|c|c|c|c|c|}
\hline Low & 753 & 1.00 & & \\
\hline Middle & 2175 & 0.61 & $0.40-0.93$ & \\
\hline High & 9064 & 0.56 & $0.39-0.81$ & \\
\hline Innovative climate ${ }^{\text {bde }}$ & & & & 0.035 \\
\hline Low & 787 & 1.00 & & \\
\hline Middle & 3703 & 0.85 & $0.53-1.37$ & \\
\hline High & 6484 & 1.04 & $0.64-1.71$ & \\
\hline Social climate ${ }^{\text {de }}$ & & & & 0.528 \\
\hline Low & 584 & 1.00 & & \\
\hline Middle & 2947 & 0.89 & $0.53-1.50$ & \\
\hline High & 7826 & 0.92 & $0.54-1.56$ & \\
\hline Human resource primacy & & & & 0.110 \\
\hline Low & 2886 & 1.00 & & \\
\hline Middle & 4566 & 0.79 & $0.59-1.04$ & \\
\hline High & 4210 & 0.79 & $0.59-1.05$ & \\
\hline Physical workload ${ }^{c}$ & & & & $<0.001$ \\
\hline Low & 7115 & 1.00 & & \\
\hline Middle & 3075 & 1.26 & $0.94-1.68$ & \\
\hline High & 1631 & 1.93 & $1.39-2.68$ & \\
\hline $\begin{array}{l}\text { Working with arms raised to or } \\
\text { above shoulder level }{ }^{c f}\end{array}$ & & & & 0.058 \\
\hline Low & 8040 & 1.00 & & \\
\hline Middle & 2434 & 1.15 & $0.84-1.58$ & \\
\hline High & 1314 & 1.21 & $0.83-1.76$ & \\
\hline
\end{tabular}

$N$ number of subjects, $H R$ hazard ratio, $\mathrm{Cl}$ confidence interval

${ }^{a}$ Adjusted for sex, age group, skill level, and sickness absence in the 3 years prior to response caused by cardiovascular disease, respiratory illnesses,

cerebrovascular disease, diabetes, or cancer

${ }^{\mathrm{b}}$ Adjusted for decision control

${ }^{\mathrm{C}}$ Adjusted for control over work intensity

${ }^{d}$ Adjusted for fair leadership

${ }^{\mathrm{e}}$ Adjusted for human resource primacy

${ }^{f}$ Adjusted for physical workload

challenge, fair leadership, and physical workload seemed to be more strongly related to disability retirement in men compared to women. In magnitude of effects, role conflict and control over work intensity revealed to be somewhat equally important to disability retirement across the sexes.

Previous studies investigating relations between psychological/social work exposures and disability retirement have often employed the "demand-control" framework. When outlining the job demand and job control dimensions, Karasek [24] stated that "a correct analysis must distinguish between two important elements of the work environment at the individual level: (1) the job demands placed on the worker and (2) the discretion permitted the worker in deciding how to meet these demands" (p. 285). Hence, the demand and control dimensions incorporate a wide range of work environment aspects. Measured with the JCQ, [6] "job demands" and "decision latitude" have 
Table 4 Psychological, social, and mechanical factors as predictors of disability retirement in men and women

\begin{tabular}{|c|c|c|c|c|c|c|c|c|c|}
\hline \multirow[b]{2}{*}{ Factor $^{a}$} & \multicolumn{4}{|l|}{ Men } & \multicolumn{4}{|c|}{ Women } & \multirow[b]{2}{*}{$\%$ difference ${ }^{d}$} \\
\hline & $\bar{N}$ & $H R^{\mathrm{bc}}$ & $99 \% \mathrm{Cl}$ & $P$-value & $\bar{N}$ & $H R^{\mathrm{bc}}$ & $99 \% \mathrm{Cl}$ & $P$-value & \\
\hline Role conflict & 5426 & 1.33 & $0.98-1.82$ & 0.017 & 6725 & 1.26 & $1.08-1.48$ & $<0.001$ & 5.26 \\
\hline Positive challenge $\mathrm{e}^{\mathrm{e}}$ & 5026 & 0.77 & $0.54-1.11$ & 0.065 & 6072 & 0.96 & $0.80-1.15$ & 0.527 & 19.79 \\
\hline Control over work intensity & 5398 & 0.83 & $0.64-1.09$ & 0.081 & 6696 & 0.81 & $0.72-0.92$ & $<0.001$ & 2.41 \\
\hline Fair leadership & 5354 & 0.74 & $0.57-0.96$ & 0.003 & 6638 & 0.86 & $0.75-0.99$ & 0.005 & 13.95 \\
\hline Physical workload ${ }^{f}$ & 5288 & 1.68 & $1.22-2.32$ & $<0.001$ & 6533 & 1.24 & $1.06-1.45$ & $<0.001$ & 26.19 \\
\hline
\end{tabular}

$N$ number of subjects, $H R$ hazard ratio, $\mathrm{Cl}$ confidence interval

${ }^{a}$ Scale scores ranging from 1 to 5 . For physical workload; 1 to 4

${ }^{\mathrm{b}}$ Risk of disability retirement per unit increase in each of the listed work exposures. HRs and Cls calculated separately for men and women

cAdjusted for age group, skill level, and sickness absence last 3 years prior to baseline response caused by cardiovascular disease, respiratory illnesses, cerebrovascular disease, diabetes, or cancer

${ }^{\mathrm{d}}$ Percentage difference in HRs between men and women

${ }^{\mathrm{e}}$ Adjusted for decision control

${ }^{f}$ Adjusted for control over work intensity

repeatedly been examined to elucidate potential separate effects of these dimensions on risk of disability retirement. Across studies of occupationally diverse populations, however, consistency of findings seems low $[3-5,25,26]$.

Results from the present study may provide some explanation to the previous inconsistencies. Decision demands, quantitative demands, and role conflict reflect aspects which are grouped together in the JCQ's job demands-dimension. While role conflict was identified as a risk factor to disability retirement, the effects of decision demands and quantitative demands revealed to be of less influence. To some extent, opposing effects were also found. Although not significantly, higher decision demands tended to be protective of disability retirement. Hence, complex decision-making and high attention demands seem to impact risk of disability retirement very differently from frequent experiences of role conflicts (e.g. incompatible requests from two or more people).

"Skill discretion" is one of two components covering JCQ's "decision latitude" [6] but few previous studies have addressed the potential independent effect of this aspect on disability retirement (see [27] for an exception). This is somewhat surprising since use of competence almost seems inseparable from the concept of "ability to perform work" [28]. Positive challenge (e.g. skills/knowledge useful in work) was identified as a clearly protective factor in the present study, a finding that arguably adds to the current state of knowledge on precursors to disability retirement.

The current study tested predictions of the leadership factors fair, empowering, and supportive leadership. Recently, an index comprising elements from fair leadership (i.e. "immediate superior treat employees fair and impartially") and supportive leadership (e.g. "get support/ help from immediate superior") was found consistently predictive of (self-reported) disability retirement in a randomly drawn Norwegian cohort [29]. Investigating the independent effects of the three above-mentioned leadership factors only fair leadership was identified as a substantial protective factor by the present study. The indicated non-significant effect of supportive leadership seems, however, to resonate with some earlier findings [30, 31].

There seems to be a paucity of studies investigating the potential discriminating effects of different sources of support on disability retirement. On the contrary, joint effects of leadership and co-worker support have repeatedly been reported and found statistically nonsignificant [3-5]. In the present study, the social climate factor encompasses support from within the work unit (e.g. "encouraging and supportive work unit climate"). However, none of the factors encompassing support at work (support from immediate supervisor and social climate) exhibited statistically significant effects on risk of disability retirement. Still, differential impact of sources of support remains an important issue as the social climate measure was designed to address aspects other than co-worker support per se.

The distributions of some of the work exposures were fairly skewed in a negative direction. In these exposures, three-level categorization resulted in relatively few observations in the reference category. This may have inflated confidence intervals. Issues with categorization of role clarity have previously been noted [15] and trichotomizing of this exposure may not have been optimal to detect statistically significant effects on disability retirement. This issue may also concern the observed negative but non-significant effect of predictability during the next month. It seems unclear, however why higher levels of predictability would contribute to an increased risk of subsequent disability retirement. One plausible explanation may be that subjects with non-optimal work ability-level, and on the path towards disability retirement, hold jobs in which working conditions are fairly stable across time. Alternatively, job tasks and the general organization of work may have been made more predictable for subjects at risk of retiring due to health 
problems. Thus, the presence of "reverse" effects cannot be ruled out. However, the present analyses were adjusted for incidences of previous sickness absence due to chronic diseases in order to make "reverse" effects a less of a concern when interpreting the results.

Previous investigations do not seem to reveal substantial sex differences in the effects of psychological and social factors on subsequent disability retirement $[3,32]$. The present results suggested that some of the specific work exposures may affect the disability risk of men stronger than the risk of women. In particular, the effects of physical workload seemed considerably stronger in men. One might suspect unequal distribution (across the sexes) of physical job demands (see e.g. [33]) to be accountable for such a finding. However, the rate of men $(14.7 \%)$ and women (13.0\%) reporting "high" physical workload were fairly equal in the current sample (analysis not shown). Also, analyses were adjusted for "skill level" which should have helped partialling out effects of occupational differences. Although some differences in magnitude of effects were discovered, all effect estimates were in the same direction across the sexes. Thus, the present findings do not provide any particular support for the notion of differentiating on sex when selecting work factors to be targeted in work place interventions.

\section{Methodological considerations}

The participants were recruited through recruiting of businesses and possibly, not all employees were sufficiently encouraged and/or reminded to participate. A higher response rate, however, would not automatically enhance the external validity (i.e. generalizability) of the present results. The diverse sample covered a wide range sectors and occupations. Still, only a randomly drawn sample from the entire working population would allow generalization of the results to the (Norwegian) working population at large.

The response rate may have compromised the internal validity of the study if, for instance, highly exposed subjects - independent of their subsequent disability status were less likely to participate, and, subjects ending up with disability pension also tended to avoid participation at baseline (due to e.g. health issues) [34]. The disability risk rate of women compared to men was in concordance with that reported in a representative Norwegian sample [29] and the numbers of new disability cases per year were comparable. Thus, it is not suspected that participants which during follow-up received disability pension were over or underrepresented in the present population. Also, previous investigations in comparable studies suggest participation not to be substantially affected by health status $[35,36]$.

According to the non-response analysis the background characteristics age, occupational class, and skill level seem to influence baseline participation status. It is unclear however if non-response based on these variables may have posed a threat to the validity of the current findings. This could be the case if these characteristics influenced the observed exposure-outcome associations. Accounting for the effects of background characteristics in the main analyses should, however, have helped control the potential influence of (self) selection bias [37].

The fact that exposure data (self-report) and outcome data (the national registry of disability compensation) were gathered by different methods allows for ruling out many of the sources of common method bias [38] as likely determinants of the observed associations. Still, bias due to subjective reporting of work exposures may exist. However, the questionnaire $\left(\mathrm{QPS}_{\text {Nordic }}\right)$ has been designed with the intention to attenuate reporting bias due to mood state and personality dispositions [14]. Participants are asked to rate items by frequency of occurrence rather than the extent to which they agree/disagree with the item content, and items are carefully worded to describe situations without referring to negative or positive emotions (satisfaction/dissatisfaction) resulting from these situations.

The present study was based on data of exposure levels measured once. During the follow-up period of (maximum) 10 years, some subjects may have experienced - for the most of this period - a different exposure level than the level reported at baseline. Thus, misclassification according to exposure level may have occurred. To address this issue, future studies with designs incorporating measures of psychological/social and mechanical exposures at several time points seem warranted. Additionally, by accounting for exposure level at multiple time points, subsequent studies should be able to address "dose-response" relationships more appropriately. Risk of disability retirement may be different for subjects reporting, for instance, constant high level of role conflict compared to subjects reporting alternations between high and middle levels of this exposure, across measurement points.

Future studies may also want to stratify by occupational group/branch to investigate if the identified predictors contribute differently to disability retirement in different occupations. In the present study, some of the branches were represented by relatively few companies with few disability cases. Thus, statistical power issues did not allow for detailed analyses, i.e. testing the effects of each exposure on disability retirement while adjusting for relevant covariates in each branch.

\section{Conclusions}

The present study contributes to existing work disabilityresearch by elucidating contributions of factors which previously have been largely unexplored or incorporated in broader assessments of psychological and social exposures. Several specific predictors were revealed, and 
knowledge of these may represent an advantage to organizational improvement programs aiming to prevent premature exit from the work force. The results of the present study suggest that practical interventions should particularly focus on reducing occupational role conflicts and physical workload, and on promoting fair leadership, positive challenge at work, and control over work intensity. It remains an important issue however if modification of the identified contributors may result in lowered risk of disability retirement.

\section{Abbreviations \\ Cl: Confidence interval; HR: Hazard ratio; N: Number; OR: Odds ratio; SD: Standard deviation}

\section{Acknowledgements}

The authors thank all participating companies, and Shahrooz Elka, Bjørn Lau, Anne Lene Andersen Watn, Margrethe Schøning, Jan Olav Christensen, and Elisabeth Petersen for their assistance in the survey administration.

\section{Funding}

This work was funded by the Research Council of Norway and the Norwegian Ministry of Labour and Social Affairs. The funders were not involved in study design/collection of data/data analysis/preparation of the manuscript.

\section{Availability of data and material}

The datasets generated and/or analyzed during the current study are not publicly available as the license to collect and store the data from The Norwegian Data Protection Authority and Regional Committees for Medical and Health Research Ethics in Norway (REC) specifically states that de-identified data are only to be available to collaborators with the National Institute of Occupational Health $(\mathrm{NIOH})$ in Norway, and upon signing a declaration of confidentiality. Thus, data may be made available on reasonable request. Any further requests concerning the availability should be directed to head of department, Stein Knardahl; stein.knardahl@stami.no or the director of the National Institute of Occupational Health - Norway, Pål Molander; pal.molander@stami.no.

\section{Authors' contributions}

JSE and SK were involved in study design. SK designed the questionnaire and had a key role in the acquisition of data. JSE analyzed and interpreted the data. JSE prepared the figures, tables, and the initial draft of the manuscript. SK and MBN critically revised drafts of the manuscript. All authors contributed to writing the final manuscript. All authors reviewed and approved the final manuscript.

\section{Competing interests}

The authors declare that they have no competing interests.

\section{Consent for publication}

Not applicable.

\section{Ethics approval and consent to participate}

The project has been approved by the Regional Committees for Medical and Health Research Ethics (REC) in Norway and has permission from The Norwegian Data Protection Authority. The research was carried out in compliance with the World Medical Association Declaration of Helsinki, and all study participants provided their informed consent.

Received: 30 September 2016 Accepted: 8 December 2016 Published online: 10 January 2017

\section{References}

1. World Health Organization. International Classification of Functioning, Disability and Health - ICF. Geneva: World Health Organization; 2001.

2. Dragano N, Schneider L. Psychosoziale Arbeitsbelastungen als Prädiktoren der krankheitsbedingten Frühberentung. [Work related psychosocial factors and the risk of early disability pensioning: a contribution to assessing the need for rehabilitation]. Rehabilitation. 2011; doi:10.1055/s-0030-1270431.
3. Canivet C, Choi B, Karasek R, Moghaddassi M, Staland-Nyman C, Ostergren PO. Can high psychological job demands, low decision latitude, and high job strain predict disability pensions? A 12-year follow-up of middle-aged Swedish workers. Int Arch Occup Environ Health. 2013; doi:10.1007/s00420-012-0766-4.

4. Labriola M, Lund T. Self-reported sickness absence as a risk marker of future disability pension. Prospective findings from the DWECS/DREAM study 1990-2004. Int J Med Sci. 2007; doi:10.7150/ijms.4.153.

5. Lahelma E, Laaksonen M, Lallukka T, Martikainen P, Pietiläinen $O$, Saastamoinen $P$ et al. Working conditions as risk factors for disability retirement: a longitudinal register linkage study. BMC Public Health. 2012; doi:10.1186/1471-2458-12-309.

6. Karasek R, Brisson C, Kawakami N, Houtman I, Bongers P, Amick B. The Job Content Questionnaire (JCQ): an instrument for internationally comparative assessments of psychosocial job characteristics. J Occup Health Psychol. 1998; doi:10.1037/1076-8998.3.4.322.

7. Ylipaavalniemi J, Kivimaki M, Elovainio M, Virtanen M, Keltikangas-Jarvinen L, Vahtera J. Psychosocial work characteristics and incidence of newly diagnosed depression: a prospective cohort study of three different models. Soc Sci Med. 2005; doi:10.1016/j.socscimed.2004.11.038.

8. Christensen JO, Knardahl S. Work and neck pain: A prospective study of psychological, social, and mechanical risk factors. PAIN. 2010; doi:10.1016/j. pain.2010.07.001.

9. Emberland JS, Knardahl S. Contribution of psychological, social, and mechanical work exposures to low work ability: a prospective study. J Occup Environ Med. 2015; doi:300-314.10.1097/jom.0000000000000353.

10. Hagen KB, Tambs K, Bjerkedal T. A prospective cohort study of risk factors for disability retirement because of back pain in the general working population. Spine. 2002; doi:10.1097/00007632-200208150-00019.

11. Krokstad S, Johnsen R, Westin S. Social determinants of disability pension: a 10-year follow-up of 62000 people in a Norwegian county population. Scand J Public Health. 2002; doi: 10.1093/ije/31.6.1183.

12. Nielsen MB, Christiansen S, Indregard A-MR, Emberland JS, Elka S, Knardahl S. The new workplace II: protocol for a prospective full-panel registry study of work factors, sickness absence, and exit from working life among Norwegian employees. SpringerPlus. 2016; doi:10.1186/s40064-016-1896-z.

13. Norwegian Labour and Welfare Administration: Benefits and services. https://www.nav.no/en/Home/Benefits+and+services/Pensions+and +pension+application+from+outside+Norway/Disability+benefit\#chapter-1 (2011). Accessed 1 Feb 2016.

14. Dallner M, Elo A-L, Gamberale F, Knardahl S, Hottinen V, Lindström K, et al. Validation of the General Nordic Questionnaire (QPS ${ }_{\text {Nordid }}$ for psychological and social factors at work. Copenhagen: Nordic Council of Ministers, Nord; 2000.

15. Wännström I, Peterson U, Asberg M, Nygren A, Gustavsson JP. Psychometric properties of scales in the General Nordic Questionnaire for Psychological and Social Factors at Work (QPS Nordic $_{\text {) }}$ : confirmatory factor analysis and prediction of certified long-term sickness absence. Scand J Psychol. 2008; doi:10.1111/j.1467-9450.2008.00697.x.

16. Therneau T, Lumley T. Survival: Survival Analysis. 2016. https://cran.r-project. org/web/packages/survival/index.html. Accessed 5 June 2016.

17. Korn EL, Graubard BI, Midthune D. Time-to-event analysis of longitudinal followup of a survey: choice of the time-scale. Am J Epidemiol. 1997;145(1):72-80.

18. Kivimäki M, Nyberg ST, Batty GD, Fransson El, Heikkilä K, Alfredsson L et al. Job strain as a risk factor for coronary heart disease: a collaborative metaanalysis of individual participant data. Lancet. 2012; doi:10.1016/S01406736(12)60994-5.

19. Virtanen M, Ferrie JE, Singh-Manoux A, Shipley MJ, Vahtera J, Marmot MG et al. Overtime work and incident coronary heart disease: the Whitehall II prospective cohort study. Eur Heart J. 2010; doi:10.1093/ eurheartj/ehq124.

20. Allebeck P, Mastekaasa A. Chapter 5. Risk factors for sick leave - general studies. Scand J Public Health. 2004; doi:10.1080/14034950410021853.

21. Goldberg P, Guéguen A, Schmaus A, Nakache J-P, Goldberg M. Longitudinal study of associations between perceived health status and self reported diseases in the French Gazel cohort. J Epidemiol Community Health. 2001; doi:10.1136/jech.55.4.233.

22. Westerlund $H$, Kivimaki M, Singh-Manoux A, Melchior M, Ferrie JE, Pentti $J$ et al. Self-rated health before and after retirement in France (GAZEL): a cohort study. Lancet. 2009; doi:10.1016/s0140-6736(09)61570-1.

23. Rothman KJ, Greenland S, Lash TL. Modern Epidemiology. Philadelphia: Lippincott Williams \& Wilkins; 2008.

24. Karasek RA. Job Demands, Job Decision Latitude, and Mental Strain: Implications for Job Redesign. Admin Sci Q. 1979; doi:10.2307/2392498. 
25. Laine S, Gimeno D, Virtanen M, Oksanen T, Vahtera J, Elovainio M et al. Job strain as a predictor of disability pension: the Finnish Public Sector Study. J Epidemiol Community Health. 2009; doi:10.1136/jech.2007.071407.

26. Mäntyniemi A, Oksanen T, Salo P, Virtanen M, Sjösten N, Pentti J et al. Job strain and the risk of disability pension due to musculoskeletal disorders, depression or coronary heart disease: a prospective cohort study of 69842 employees. Occup Environ Med. 2012; doi:10.1136/oemed-2011-100411.

27. Lund T, Iversen L, Poulsen KB. Work environment factors, health, lifestyle and marital status as predictors of job change and early retirement in physically heavy occupations. Am J Ind Med. 2001; doi:10.1002/ajim.1084.

28. Tengland PA. The concept of work ability. J Occup Rehabil. 2011; doi:10. 1007/s10926-010-9269-x.

29. Sterud T. Work-related psychosocial and mechanical risk factors for work disability: a 3-year follow-up study of the general working population in Norway. Scand J Work Environ Health. 2013; doi:10.5271/sjweh.3359.

30. Hinkka K, Kuoppala J, Vaananen-Tomppo I, Lamminpaa A. Psychosocial work factors and sick leave, occupational accident, and disability pension: a cohort study of civil servants. J Occup Environ Med. 2013; doi:10.1097/JOM. Ob013e31827943fe.

31. Sinokki M, Hinkka K, Ahola K, Gould R, Puukka P, Lonnqvist J et al. Social support as a predictor of disability pension: the Finnish Health 2000 study. J Occup Environ Med. 2010; doi:10.1097/JOM.0b013e3181e79525.

32. Mein G, Martikainen P, Stansfeld SA, Brunner EJ, Fuhrer R, Marmot MG. Predictors of early retirement in British civil servants. Age Ageing. 2000; doi: 10.1093/ageing/29.6.529.

33. Campos-Serna J, Ronda-Pérez E, Artazcoz L, Moen BE, Benavides FG. Gender inequalities in occupational health related to the unequal distribution of working and employment conditions: a systematic review. Int J Equity Health. 2013; doi:10.1186/1475-9276-12-57.

34. Criqui $\mathrm{MH}$. Response bias and risk ratios in epidemiologic studies. Am J Epidemiol. 1979;109(4):394-9.

35. Laaksonen M, Aittomäki A, Lallukka T, Rahkonen O, Saastamoinen P, Silventoinen $\mathrm{K}$ et al. Register-based study among employees showed small nonparticipation bias in health surveys and check-ups. J Clin Epidemiol. 2008; doi:10.1016/j.jclinepi.2007.09.010.

36. Nielsen MB, Knardahl S. The healthy worker effect: do health problems predict participation rates in, and the results of, a follow-up survey? Int Arch Occup Environ Health. 2015; doi:10.1007/s00420-015-1066-6.

37. Pearce $\mathrm{N}$, Checkoway $\mathrm{H}$, Kriebel D. Bias in occupational epidemiology studies. Occup Environ Med. 2007; doi:10.1136/oem.2006.026690.

38. Podsakoff PM, Mackenzie SB, Lee JY, Podsakoff NP. Common method biases in behavioral research: a critical review of the literature and recommended remedies. J Appl Psychol. 2003; doi:10.1037/0021-9010.88.5.879.

\section{Submit your next manuscript to BioMed Central and we will help you at every step:}

- We accept pre-submission inquiries

- Our selector tool helps you to find the most relevant journal

- We provide round the clock customer support

- Convenient online submission

- Thorough peer review

- Inclusion in PubMed and all major indexing services

- Maximum visibility for your research

Submit your manuscript at www.biomedcentral.com/submit 